ASTHMA

\title{
Directly measured second hand smoke exposure and asthma health outcomes
}

\author{
M D Eisner, J Klein, S K Hammond, G Koren, G Lactao, C Iribarren
}

Thorax 2005;60:814-821. doi: 10.1136/thx.2004.037283

See end of article for authors' affiliations .....................

Correspondence to: DrM M Eisner, University of California, San Francisco, 350 Parnassus Avenue, Ste 609, San Francisco, CA 94117 USA; eisner@itsa.ucsf.edu

Received

10 November 2004

Accepted 26 April 2005
Background: Because they have chronic airway inflammation, adults with asthma could have symptomatic exacerbation after exposure to second hand smoke (SHS). Surprisingly, data on the effects of SHS exposure in adults with asthma are quite limited. Most previous epidemiological studies used self-reported SHS exposure which could be biased by inaccurate reporting. In a prospective cohort study of adult nonsmokers recently admitted to hospital for asthma, the impact of SHS exposure on asthma health outcomes was examined.

Methods: Recent SHS exposure during the previous 7 days was directly measured using a personal nicotine badge $(n=189)$ and exposure during the previous 3 months was estimated using hair nicotine and cotinine levels $(n=138)$. Asthma severity and health status were ascertained during telephone interviews, and subsequent admission to hospital for asthma was determined from computerised utilisation databases.

Results: Most of the adults with asthma were exposed to SHS, with estimates ranging from $60 \%$ to $83 \%$ depending on the time frame and methodology. The highest level of recent SHS exposure, as measured by the personal nicotine badge, was related to greater asthma severity (mean score increment for highest tertile of nicotine level 1.56 points; $95 \% \mathrm{Cl} 0.18$ to 2.95 ), controlling for sociodemographic covariates and previous smoking history. Moreover, the second and third tertiles of hair nicotine exposure during the previous month were associated with a greater baseline prospective risk of hospital admission for asthma (HR 3.73; $95 \% \mathrm{Cl} 1.04$ to 13.30 and $\mathrm{HR} 3.61 ; 95 \% \mathrm{Cl} 1.0$ to 12.9 , respectively).

Conclusions: Directly measured SHS exposure appears to be associated with poorer asthma outcomes. In public health terms, these results support efforts to prohibit smoking in public places.
A complex mixture of over 4000 chemical compounds, second hand tobacco smoke (SHS) contains potent respiratory irritants such as sulfur dioxide, ammonia, formaldehyde, and acrolein. ${ }^{1}$ Because they have chronic airway inflammation, adults with asthma could have symptomatic exacerbation after SHS exposure. Supporting this contention, extensive evidence implicates SHS exposure as a cause of asthma exacerbation among children. ${ }^{1}$ In contrast, data on the effects of SHS exposure in adults with asthma are surprisingly limited..$^{2-7}$ Moreover, most previous epidemiological studies used self-reported measurement of SHS exposure which could be biased by inaccurate recollection or reporting of SHS exposure. Direct measurement of SHS exposure using a personal nicotine badge and hair analysis provides an objective unbiased assessment of SHS exposure. In a prospective cohort study of adults with severe asthma, we studied the impact of SHS exposure, which was directly measured, on asthma health outcomes.

\section{METHODS}

\section{Overview}

The data used were from a prospective cohort study of adult members of a closed panel managed care organisation admitted to hospital for asthma during a 4 year period. After hospital discharge we conducted structured telephone interviews and direct SHS exposure assessment using personal nicotine badges and hair analysis of nicotine and cotinine. This combined methodology provided estimates of SHS exposure for a time window ranging from the previous 7 days to previous 3 months. We examined the impact of directly measured SHS exposure on asthma severity, health status, and the prospective risk of future hospital admissions for asthma. The study was approved by the University of
California, San Francisco Committee on Human Research and the Kaiser Foundation Research Institute's institutional review board.

\section{Subject recruitment}

Adult members of Kaiser Permanente (KP), the nation's largest non-profit managed care organisation, were studied. In Northern California, the Kaiser Permanente Medical Care Program (KPMCP) provides the full spectrum of primary to tertiary care to approximately 3.1 million members. In Northern California KP's share of the regional population ranges from $25 \%$ to $30 \%{ }^{8}$ The demographic characteristics of KP membership are similar to the overall Northern California population except for the extremes of income distribution. ${ }^{9}$ Of the 2.0 million adult KP members ( $\geqslant 18$ years), an estimated 160307 (8.1\%) have asthma.

On a rolling monthly basis we identified all adult KP members ( $\geqslant 18$ years) admitted to any Northern California KP hospital with a principal Ninth International Classification of Diseases (ICD-9) discharge diagnosis code for asthma (codes 493.00 to 493.99 ) during a 4 year period beginning in April 2000. We also included KP members admitted to hospital with a secondary ICD-9 discharge diagnosis code for asthma and a principal ICD-9 code for acute asthma related respiratory conditions (pneumonia, influenza with pneumonia, acute upper respiratory infection, acute bronchitis and bronchiolitis, pulmonary collapse, respiratory failure, other pulmonary insufficiency, pneumothorax, and viral infection). Persons with a primary or secondary discharge diagnosis code for chronic bronchitis (491.xx), emphysema (492.xx), or chronic airway obstruction (496.xx) were excluded. In addition, all subjects reported a 
physician diagnosis of asthma at the time of telephone interview.

Beginning in April 2000, we attempted to recruit all eligible adults who were admitted to the intensive care unit (ICU) for asthma who were considered to have more severe asthma. ${ }^{10}$ To broaden the spectrum of asthma severity, in September 2000 we also began recruiting an additional random sample of all eligible adults admitted to hospital for asthma without ICU admission (non-ICU group). In October 2002 we began recruiting all eligible adults who were admitted to hospital for asthma, rather than just a random sample of the non-ICU group. The complete cohort included 865 subjects who underwent structured telephone interviews (53\% completion rate).

At the end of the interview the 778 subjects who indicated no current smoking were invited to participate in the direct SHS monitoring programme (see below). Of these participants, $189(24 \%)$ wore and returned the nicotine badge for 7 days and $138(18 \%)$ returned hair samples that could be analysed for nicotine and cotinine. Overall, the subjects who participated in direct SHS monitoring were very similar to the cohort of non-smokers who did not participate (table 1). Subjects who provided a hair sample were slightly older (mean 2 years) than those who did not. The participants in both the nicotine badge and hair sample analyses were less likely to indicate non-white race ethnicity. Otherwise, participants in the direct SHS monitoring programme were similar to non-participants, including severity of asthma and physical state of health. To take non-response into account, sampling weights were developed using all the personal characteristics in table 1 . The weighted analysis was not substantively different from the unweighted analysis, so only the unweighted analysis is reported here.

\section{Validation of asthma diagnosis}

To validate the diagnosis of asthma we selected a stratified random sample of 100 patient medical records from subjects admitted to the ICU for asthma and those hospitalised without ICU admission for asthma. The records were abstracted by a single trained medical record reviewer for a period ranging from 12 months before the index hospital admission until 6 months following the index date. The reviewer evaluated the records for a recorded physician diagnosis of asthma and related conditions, including exercise induced asthma and reactive airway disease. Of the 100 medical records, 99 had a physician's diagnosis of asthma recorded in the record; for the other subject a diagnosis of reactive airway disease was recorded. These data support the validity of our algorithm for identifying adults with asthma.

\section{Measurement of direct SHS exposure}

A combined approach was used to measure SHS exposure directly. Each subject was instructed to wear the personal nicotine badge monitor during his or her regular activities for 7 days. The passive monitor, which has been previously described, ${ }^{11}{ }^{12}$ samples nicotine from ambient air. A polystyrene cassette $4 \mathrm{~cm}$ in diameter holds a filter treated with sodium bisulfate and a membrane filter functions as a windscreen. Ambient nicotine diffuses to the treated filter where it is trapped. The collected nicotine is analysed by gas chromatography with nitrogen selective detection. The passive monitors have a limit of detection of $<0.01 \mu \mathrm{g}$ per filter and a coefficient of variability of 0.11 for replicate analysis. ${ }^{12}$

Hair nicotine and cotinine were measured because they both accumulate in growing hair, reflecting a longer time window of exposure. ${ }^{13-19}$ Nicotine accumulates in hair primarily by direct absorption from ambient air; there is a direct linear relationship between the duration and concentration of exposure to ambient nicotine and hair nicotine level. ${ }^{132021}$ Cotinine, which is the major metabolite of nicotine, is incorporated into the growing hair shaft and reflects the area under the plasma concentration versus time curve. ${ }^{13}$ Both hair nicotine and cotinine concentrations have been shown to distinguish passive smokers from active and non-smokers. ${ }^{17} 22$

Hair was sampled and analysed using previously described techniques. ${ }^{15} 182223$ Each participating subject was instructed to cut approximately 10 hair shafts from the posterior vertex, as close as possible to the scalp. Because the hair test aimed to assess SHS exposure, the samples were analysed without prior washing that could remove nicotine adsorbed from ambient air. Each sample was cut into two segments for segmental analysis. Based on the growth rate of hair, which is about $1 \mathrm{~cm}$ per month, the first $1 \mathrm{~cm}$ segment approximately reflects SHS exposure during the previous month, whereas the $2-3 \mathrm{~cm}$ segment corresponds to the preceding 2 month period (that is, previous second to third months).

Hair nicotine and cotinine concentrations were determined by radioimmunoassay using techniques developed by the reference laboratory. Each portion of the hair to be analysed was minced with fine scissors into $1 \mathrm{~mm}$ segments and 3$7 \mathrm{mg}$ of the hair was accurately weighed on an analytical

Table 1 Personal characteristics of the cohort of non-smoking adults with asthma, including participants in the direct SHS monitoring programme

\begin{tabular}{|c|c|c|c|}
\hline & $\begin{array}{l}\text { Entire cohort of } \\
\text { current non-smokers } \\
(\mathrm{n}=778) \dagger\end{array}$ & $\begin{array}{l}\text { Nicotine badge } \\
\text { monitoring } \\
(\mathrm{n}=189)\end{array}$ & $\begin{array}{l}\text { Hair sample } \\
(n=138)\end{array}$ \\
\hline Mean (SD) age (years) & $61(16)$ & $63(14)$ & $65(13)^{*}$ \\
\hline Sex (female) & $546(70 \%)$ & $125(66 \%)$ & $97(70 \%)$ \\
\hline Race (non-white) & $310(40 \%)$ & $56(30 \%)^{*}$ & $44(32 \%)^{*}$ \\
\hline \multicolumn{4}{|l|}{ Educational attainment } \\
\hline High school or less & $150(19 \%)$ & $35(19 \%)$ & $26(19 \%)$ \\
\hline Some college & $442(56 \%)$ & $104(55 \%)$ & $69(50 \%)$ \\
\hline College or graduate degree & $186(24 \%)$ & $50(26 \%)$ & $43(31 \%)$ \\
\hline Married or cohabiting with partner & $470(60 \%)$ & $121(64 \%)$ & $88(63 \%)$ \\
\hline Past cigarette smoking & $478(61 \%)$ & $117(62 \%)$ & $83(60 \%)$ \\
\hline Mean (SD) severity of asthma score & $12.7(4.1)$ & $12.9(3.8)$ & $12.9(3.9)$ \\
\hline Physical health status (SF-12) & $35(12)$ & $34(10)$ & $34(11)$ \\
\hline \multicolumn{4}{|c|}{$\begin{array}{l}\text { Unless otherwise indicated, the data are presented as } n(\%) \text {. } \\
{ }^{*} p<0.05 v \text { entire cohort of non-smokers (for example, nicotine badge group } v \text { entire cohort who did not wear } \\
\text { nicotine badge; hair sample group } v \text { entire cohort who did not provide hair sample). } \\
\dagger \text { Entire cohort } n=865 \text { ( } 87 \text { current smokers ( } 85 \text { who reported smoking and two who had hair nicotine levels } \\
\text { consistent with active smoking) were excluded). }\end{array}$} \\
\hline
\end{tabular}


balance. The hair was placed in a glass container with $1 \mathrm{ml}$ sodium hydroxide $0.6 \mathrm{~N}$ and digested overnight at $50^{\circ} \mathrm{C}$. The following day the solution was neutralised with a small volume (50-70 $\mu \mathrm{l})$ of concentrated hydrochloric acid and $100 \mu \mathrm{l}$ aliquots of the neutral solution were used to measure nicotine or cotinine concentrations by radioimmunoassay. For both analytes the same Isogel-Tris buffer was used at $\mathrm{pH}$ 7.4 with a $0.1 \%$ gelatin content. Tritiated nicotine/cotinine were used as radiolabelled tracers; the antiserum specific for nicotine/cotinine was raised in rabbits. To separate the antibody bound nicotine/cotinine from the free analyte, the same anti-rabbit gamma globulin raised in goats was used for both analytes. For quantification, nicotine $(0.2-50 \mathrm{ng} / \mathrm{ml})$ or cotinine $(0.1-20 \mathrm{ng} / \mathrm{ml})$ standards were used in hair digest totally void of nicotine or cotinine to account for any matrix effect. The results are expressed as ng analyte per mg hair. The quantification limit of the assay is $0.04 \mathrm{ng} / \mathrm{mg}$ of hair for nicotine and $0.02 \mathrm{ng} / \mathrm{mg}$ of hair for cotinine (for $5 \mathrm{mg}$ of hair).

Because they directly reflect ambient SHS levels, the personal badge nicotine monitor and hair nicotine levels are best considered measures of exposure. Hair cotinine, because it requires uptake and metabolism of nicotine, is a measure of SHS dose.

\section{Self-reported SHS exposure}

A validated survey instrument was used to measure selfreported recent SHS exposure. ${ }^{24}$ The instrument assesses exposure during the previous 7 days in six microenvironments: the respondent's home, another person's home, travelling in a car or another vehicle, workplace (including outdoor smoking areas), bars and nightclubs, and other locations. For each microenvironment the total duration of exposure during the previous week was elicited. An overall measure of SHS exposure was created by summing the duration of exposure in each microenvironment. For the present study, self-reported SHS exposure was defined as one or more hours of exposure during the previous 7 days.

\section{Other predictor variables (covariates)}

Structured telephone interviews ascertained age, sex, race ethnicity, educational attainment, and marital status. Cigarette smoking was measured using questions developed for the National Health Interview Survey. ${ }^{25}$ As in previous studies, we defined educational attainment as high school or less, some college, or college/graduate degree. ${ }^{26}$ Race ethnicity and marital status were classified as described previously. ${ }^{26}$

\section{Asthma health outcomes: disease severity, quality of life, and physical health status}

Asthma severity was measured using a previously developed and validated 13 item disease-specific severity of asthma score based on frequency of current asthma symptoms (daytime or nocturnal), use of systemic corticosteroids, use of other asthma medications (besides systemic corticosteroids), and history of hospital admissions and intubation. ${ }^{27} 28$ Possible total scores range from 0 to 28 , with higher scores reflecting more severe asthma. Previous work has established the reliability, concurrent validity, and predictive validity of the severity score. ${ }^{27} 28$

Asthma-specific quality of life was assessed using the Marks Asthma Quality of Life Questionnaire (AQLQ), a 20item questionnaire that measures the physical, emotional, and social impact of asthma. ${ }^{29}$ Previous work has confirmed the validity and responsiveness of the AQLQ to change in asthma status. ${ }^{30}{ }^{31}$ Higher scores represent poorer asthmaspecific quality of life.

Generic physical health status was measured using the SF12 questionnaire. ${ }^{32}$ The physical component summary score, which was defined from the original eight SF-36 subscales by factor analysis, measures the underlying physical dimensions of health. Previous work has confirmed the validity of the SF12 instrument in adult asthma. ${ }^{33}$ Higher scores reflect more favourable health status.

\section{Longitudinal outcomes: admission to hospital for asthma}

The longitudinal study outcome was admission to hospital for asthma that occurred after the index hospital admission and after the baseline study interview (the "baseline" period). Asthma related admission to hospital was defined as one or more admissions with a principal discharge diagnosis code for asthma (ICD-9 code 493.xx) or a secondary diagnosis code for asthma with a primary diagnosis of a related respiratory condition (see above).

\section{Statistical analysis}

Statistical analysis was conducted using SAS software Version 8.2 (SAS Institute Inc, Cary, NC). Bivariate analysis was performed using the $t$ test for continuous normally distributed variables and the $\chi^{2}$ test for categorical variables. Directly measured SHS exposure by nicotine badge, hair nicotine, and hair cotinine were divided into tertiles based on their distribution (the lowest tertile included subjects with no exposure and very low exposure levels). Linear regression analysis was used to examine the association between directly measured SHS exposure and severity of asthma, asthma-specific quality of life, and physical health status. Multivariate linear regression analysis was used to control for factors that may confound the relationship between SHS exposure and health outcomes, including age, sex, race ethnicity, educational attainment, household income, marital status, and previous smoking history. ${ }^{64}$ Standard regression diagnostics were performed to verify model assumptions.

We used Cox proportional hazards regression analysis to evaluate the prospective impact of directly measured SHS exposure on the subsequent risk of admission to hospital for asthma during longitudinal follow up. Subjects were censored for death or termination of health plan membership. Multivariate proportional hazards analysis was used to control for the same covariates. The exact method was used for handling ties.

The proportional hazards assumption was tested by including time-SHS exposure interaction terms in the Cox model. ${ }^{35}$ The proportional hazards assumption was violated for one model (hair nicotine, past month). In this model, SHS exposure was included as a time dependent covariate to take the non-proportionality into account. ${ }^{36}$

Before conducting the study, statistical power was estimated for a two tailed $\alpha$ of 0.05 and $\beta$ of 0.20 (power $80 \%$ ). The study was powered to detect a 1.4 point increment in severity of asthma score and a relative risk of readmission to hospital of 1.8 .

\section{RESULTS}

\section{Prevalence of SHS exposure}

A minority of the overall cohort of adults with asthma reported at least 1 hour of SHS exposure during the previous week (15.4\%; $95 \%$ CI 13.0 to 18.2 ). Similarly, only $12.2 \%$ and $11.6 \%$ of nicotine badge and hair sample participants, respectively, reported any recent SHS exposure. In contrast, the majority (72\%; 95\% CI 66 to 79 ) of adults with asthma had measurable exposure during the previous week by the personal nicotine badge analysis (table 2 ). The prevalence of SHS exposure was higher among those with the greatest asthma severity (as indicated by ICU admission for asthma) than among those admitted to hospital without ICU admission $(p=0.044)$. The intensity of exposure, which 
Table 2 Prevalence and intensity of directly measured SHS exposure among 189 non-smoking adults with asthma during the previous 7 days: personal nicotine badge analysis

\begin{tabular}{lllllll}
\hline & & \multicolumn{4}{l}{ Nicotine concentration $\left(\mu \mathrm{g} / \mathrm{m}^{3}\right)$ among } & those with any exposure \\
\cline { 3 - 7 } Condition & Prevalence & Minimum & 25th percentile & Median & 75th percentile & Maximum \\
\hline ICU $(n=30)$ & $26(87 \%)$ & 0.03 & 0.10 & 0.24 & 0.32 & 3.16 \\
Hospital only $(n=159)$ & $111(70 \%)$ & 0.02 & 0.05 & 0.11 & 0.30 & 9.82 \\
Total $(\mathrm{n}=189)$ & $137(72 \%)$ & 0.02 & 0.06 & 0.12 & 0.32 & 9.82 \\
\hline
\end{tabular}

$p=0.044$ for comparison of prevalence in ICU $v$ hospital only group (likelihood ratio $\chi^{2}$ test).

$p=0.027$ for comparison of nicotine concentration in ICU $v$ hospital only group (Kruskal-Wallis test).

was also highest for asthmatics admitted to the ICU, is also shown in table 2 .

Using hair nicotine analysis, we estimated an SHS exposure prevalence of $60 \%$ (95\% CI 51 to 68 ) during the past month and $69 \%$ (95\% CI 60 to 77 ) during the past 23 months (table 3 ). The prevalence of SHS exposure was higher using analysis of hair cotinine $(75 \%$ for the past month (95\% CI 67 to 82 ) and $83 \%$ for the past $2-3$ months (95\% CI 75 to 89$)$ ). There were no statistical differences between the ICU and hospital only groups ( $\mathrm{p}>0.50$ in all cases).

Hair nicotine (a measure of SHS exposure) and hair cotinine (a measure of SHS dose) were moderately correlated at both the earlier $(r=0.63, \mathrm{p}<0.0001)$ and later time points $(r=0.67, \mathrm{p}<0.0001$; table 4$)$. The estimate of hair nicotine exposure was highly stable during the two time periods $(r=0.80)$. Hair cotinine levels were also highly stable $(r=0.84)$.

\section{Directly measured SHS exposure/dose and asthma health outcomes}

Recent SHS exposure, as measured by the personal nicotine badge, was related to asthma severity (table 5). The highest tertile of SHS exposure was associated with a greater severity of asthma score (mean increment 1.56 ; $95 \%$ CI 0.18 to 2.95), controlling for age, sex, race, educational attainment, marital status, and previous smoking history. Although asthmaspecific quality of life and physical health status scores were higher among subjects in the highest exposure tertile, the confidence intervals were wide and included no effect.
The hair nicotine level during the previous month was not associated with asthma severity, asthma-specific quality of life, or physical health status (table 5). In the analysis of hair nicotine levels for the previous 2-3 months, there was a suggestion that the highest exposure tertile was associated with greater asthma severity (mean score increment 1.67; $95 \%$ CI -0.10 to 3.44 ), controlling for the same covariates.

When hair cotinine was examined as a measure of SHS dose, the second tertile was associated with greater asthma severity (mean increment $1.79 ; 95 \%$ CI 0.16 to 3.42 ; table 5 ). There were no other clear relationships between hair cotinine levels and measures of asthma status.

\section{SHS exposure/dose and risk of hospital admission}

There was no relation between recent SHS exposure measured by nicotine badge and the subsequent risk of admission to hospital (table 6). In contrast, the second and third tertiles of hair nicotine exposure during the previous month were associated with a greater prospective risk of admission to hospital for asthma (HR 3.73; 95\% CI 1.04 to 13.3 and HR $3.61 ; 95 \%$ CI 1.01 to 12.9 , respectively). This model required time-dependent terms for SHS exposure to take the non-proportional hazards into account. Consequently, these hazard ratios represent the risk of hospital admission at baseline; the risk diminished thereafter. For example, for the second tertile at 180 days the HR was 2.10, and at 365 days the HR was 1.16. For the third tertile at 180 days the HR was 1.81, and at 365 days the HR was 0.89 .

Table 3 Prevalence and intensity of directly measured SHS exposure among non-smoking adults with asthma during the previous 3 months: hair analysis

\begin{tabular}{|c|c|c|c|c|}
\hline \multirow[b]{2}{*}{ Hair measurement† } & \multirow[b]{2}{*}{ Prevalence } & \multicolumn{3}{|c|}{ Nicotine concentration among those with any exposure $(\mathrm{ng} / \mathrm{mg}$ hair) } \\
\hline & & Minimum & Median & Maximum \\
\hline \multicolumn{5}{|l|}{ Nicotine } \\
\hline \multicolumn{5}{|l|}{ Previous month } \\
\hline$I C U(n=20)$ & $11(55 \%)$ & 0.06 & 0.28 & 1.41 \\
\hline Hospital only $(n=118)$ & $72(61 \%)$ & 0.03 & 0.15 & 3.15 \\
\hline Total $(n=138)$ & $83(60 \%)$ & 0.03 & 0.16 & 3.15 \\
\hline \multicolumn{5}{|l|}{ Previous $2-3$ months } \\
\hline ICU $(n=19)$ & $12(63 \%)$ & 0.07 & 0.21 & 1.45 \\
\hline Hospital only $(n=105$ ) & $74(70 \%)$ & 0.02 & 0.17 & 4.00 \\
\hline Total $(n=124)$ & $86(69 \%)$ & 0.02 & 0.18 & 4.00 \\
\hline \multicolumn{5}{|l|}{ Cotinine } \\
\hline \multicolumn{5}{|l|}{ Previous month } \\
\hline ICU $(n=20)$ & $15(75 \%)$ & 0.02 & 0.10 & 0.50 \\
\hline Hospital only $(n=118)$ & $88(75 \%)$ & 0.01 & 0.085 & 0.78 \\
\hline Total $(n=138)$ & $103(75 \%)$ & 0.01 & 0.09 & 0.78 \\
\hline \multicolumn{5}{|l|}{ Previous 2-3 months } \\
\hline ICU $(n=19)$ & 15 (79\%) & 0.02 & 0.09 & 0.61 \\
\hline Hospital only $(n=105$ ) & $88(84 \%)$ & 0.02 & 0.09 & 1.11 \\
\hline Total $(n=124)$ & $103(83 \%)$ & 0.02 & 0.09 & 1.11 \\
\hline
\end{tabular}


Table 4 Relationship between SHS exposure and dose measurements among adults with asthma

\begin{tabular}{|c|c|c|c|c|c|c|}
\hline & $\begin{array}{l}\text { Nicotine badge } \\
\text { (past week) }\end{array}$ & $\begin{array}{l}\text { Hair nicotine } \\
\text { (past month) }\end{array}$ & $\begin{array}{l}\text { Hair nicotine } \\
\text { (past 2-3 months) }\end{array}$ & $\begin{array}{l}\text { Hair cotinine } \\
\text { (past month) }\end{array}$ & $\begin{array}{l}\text { Hair cotinine } \\
\text { (past 2-3 months) }\end{array}$ & $\begin{array}{l}\text { Self-reported hours } \\
\text { of SHS exposure } \\
\text { (past week) }\end{array}$ \\
\hline Nicotine badge (past week) & 1.0 & $\begin{array}{l}0.20 \\
p=0.019\end{array}$ & $\begin{array}{l}0.17 \\
p=0.059\end{array}$ & $\begin{array}{l}0.16 \\
p=0.065\end{array}$ & $\begin{array}{l}0.14 \\
p=0.13\end{array}$ & $\begin{array}{l}0.27 \\
0.0009\end{array}$ \\
\hline Hair nicotine (past month) & - & 1.0 & $\begin{array}{l}0.80 \\
p<0.0001\end{array}$ & $\begin{array}{l}0.63 \\
p<0.0001\end{array}$ & $\begin{array}{l}0.65 \\
p<0.0001\end{array}$ & $\begin{array}{l}0.24 \\
0.0043\end{array}$ \\
\hline Hair nicotine (past 3 months) & - & - & 1.0 & $\begin{array}{l}0.46 \\
p<0.0001\end{array}$ & $\begin{array}{l}0.67 \\
p<0.0001\end{array}$ & $\begin{array}{l}0.25 \\
0.0053\end{array}$ \\
\hline Hair cotinine (past month) & - & - & - & 1.0 & $\begin{array}{l}0.84 \\
p<0.0001\end{array}$ & $\begin{array}{l}0.26 \\
0.0017\end{array}$ \\
\hline Hair cotinine (past 3 months) & - & - & - & - & 1.0 & $\begin{array}{l}0.25 \\
0.0041\end{array}$ \\
\hline $\begin{array}{l}\text { Self-reported hours of SHS } \\
\text { exposure (past week) }\end{array}$ & - & - & - & - & - & 1.0 \\
\hline
\end{tabular}

Values shown are Spearman correlations and $p$ values.

There was also a suggestion that hair cotinine levels during the previous $2-3$ months were related to a greater prospective risk of asthma-related hospital admission, although the confidence intervals did not exclude the possibility of no relationship (table 6). In particular, the second and third tertile of hair cotinine appeared to be related to a higher risk of hospital admission (HR 2.08; 95\% CI 0.96 to 4.54 and HR $1.80 ; 95 \%$ CI 0.81 to 4.00 , respectively).

\section{DISCUSSION}

We report the first study to assess the effects of objectively measured SHS exposure on a substantial cohort of adults with asthma. Despite the fact that they had chronic respiratory disease, SHS exposure was common among adults with severe asthma, including those with severe disease requiring ICU admission. Moreover, survey based exposure assessment resulted in a striking underestimation of the prevalence of SHS exposure. Although the results vary by direct measurement technique and were not statistically significant in all cases, SHS exposure was generally associated with greater asthma severity and a greater risk of severe asthma exacerbation resulting in admission to hospital.

In a previous study we found evidence that SHS exposure was longitudinally associated with poorer health outcomes among adults with asthma. ${ }^{6}$ Other epidemiological studies have also suggested that SHS exposure may exacerbate adult asthma. ${ }^{2-5} 3738$ These studies, however, all used self-reported SHS exposure which could have resulted in exposure misclassification. In a previous small study of 50 adults with asthma from a different cohort, we showed that SHS exposure measured by the nicotine badge test was associated with more asthma symptoms and rescue medication use. ${ }^{24}$ Because we used direct SHS exposure measurement in a large prospective cohort, the present study provides important

Table 5 Directly measured SHS exposure and asthma health status

\begin{tabular}{|c|c|c|c|}
\hline Exposure measurement & $\begin{array}{l}\text { Severity of asthma score } \\
\text { Mean difference* }(95 \% \mathrm{Cl})\end{array}$ & $\begin{array}{l}\text { Asthma-specific quality of life score } \\
\text { Mean difference }{ }^{*}(95 \% \mathrm{CI})\end{array}$ & $\begin{array}{l}\text { Physical health status score } \\
\text { Mean difference }(95 \% \mathrm{Cl})\end{array}$ \\
\hline $\begin{array}{l}\text { Nicotine badge (previous week) } \\
\text { First tertile }\left(0-0.03 \mu \mathrm{g} / \mathrm{m}^{3}\right) \\
\text { Second tertile }\left(0.04-0.13 \mu \mathrm{gg} / \mathrm{m}^{3}\right) \\
\text { Third tertile }\left(0.14-9.82 \mu \mathrm{gg} / \mathrm{m}^{3}\right)\end{array}$ & $\begin{array}{l}\text { Referent } \\
0.32(-1.03 \text { to } 1.66) \\
1.56(0.18 \text { to } 2.95) \ddagger\end{array}$ & $\begin{array}{l}\text { Referent } \\
-0.20(-4.62 \text { to } 4.22) \\
2.63(-1.92 \text { to } 7.18)\end{array}$ & $\begin{array}{l}\text { Referent } \\
0.91(-2.64 \text { to } 4.47) \\
-2.34(-6.00 \text { to } 1.32)\end{array}$ \\
\hline $\begin{array}{l}\text { Hair nicotine (previous montht) } \\
\text { First tertile }(0 \mathrm{ng} / \mathrm{mg}) \text { ) } \\
\text { Second tertile }(0.01-0.12 \mathrm{ng} / \mathrm{mg}) \\
\text { Third tertile }(0.13-3.15 \mathrm{ng} / \mathrm{mg})\end{array}$ & $\begin{array}{l}\text { Referent } \\
0.56(-1.18 \text { to } 2.29) \\
0.63(-1.09 \text { to } 2.34)\end{array}$ & $\begin{array}{l}\text { Referent } \\
-0.77(-5.81 \text { to } 4.27) \\
-0.26(-5.24 \text { to } 4.71)\end{array}$ & $\begin{array}{l}\text { Referent } \\
2.05(-2.32 \text { to } 6.41) \\
-1.20(-5.52 \text { to } 3.11)\end{array}$ \\
\hline $\begin{array}{l}\text { Hair nicotine (previous } 2-3 \text { monthst) } \\
\text { First tertile }(0-0.02 \mathrm{ng} / \mathrm{mg}) \\
\text { Second tertile }(0.03-0.19 \mathrm{ng} / \mathrm{mg}) \\
\text { Third tertile }(0.20-4.0 \mathrm{ng} / \mathrm{mg})\end{array}$ & $\begin{array}{l}\text { Referent } \\
-0.08(-1.83 \text { to } 1.67) \\
1.67(-0.10 \text { to } 3.44) \ddagger\end{array}$ & $\begin{array}{l}\text { Referent } \\
-0.17(-5.73 \text { to } 5.39) \\
1.17(-4.46 \text { to } 6.80)\end{array}$ & $\begin{array}{l}\text { Referent } \\
-0.22(-4.85 \text { to } 4.41) \\
-3.57(-8.26 \text { to } 1.11)\end{array}$ \\
\hline $\begin{array}{l}\text { Hair cotinine (previous montht) } \\
\text { First tertile }(0-0.02 \mathrm{ng} / \mathrm{mg}) \\
\text { Second tertile }(0.03-0.10 \mathrm{ng} / \mathrm{ml}) \\
\text { Third tertile }(0.11-0.78 \mathrm{ng} / \mathrm{ml})\end{array}$ & $\begin{array}{l}\text { Referent } \\
1.79(0.16 \text { to } 3.42) \\
0.67(-1.03 \text { to } 2.38)\end{array}$ & $\begin{array}{l}\text { Referent } \\
2.15(-2.64 \text { to } 6.95) \\
0.73(-4.29 \text { to } 5.75)\end{array}$ & $\begin{array}{l}\text { Referent } \\
-1.96(-6.15 \text { to } 2.22) \\
-2.38 \text { (-6.75 to } 2.22)\end{array}$ \\
\hline $\begin{array}{l}\text { Hair cotinine (previous } 2-3 \text { monthst) } \\
\text { First tertile }(0-0.03 \mathrm{ng} / \mathrm{ml}) \\
\text { Second tertile }(0.04-0.10 \mathrm{ng} / \mathrm{ml}) \\
\text { Third tertile }(0.11-1.11 \mathrm{ng} / \mathrm{ml})\end{array}$ & $\begin{array}{l}\text { Referent } \\
1.11(-0.61 \text { to } 2.84) \\
1.04(-0.76 \text { to } 2.85)\end{array}$ & $\begin{array}{l}\text { Referent } \\
3.32(-2.06 \text { to } 8.70) \\
2.45(-3.07 \text { to } 8.08)\end{array}$ & $\begin{array}{l}\text { Referent } \\
-3.07(-7.79 \text { to } 1.65) \\
-3.74(-8.71 \text { to } 1.23)\end{array}$ \\
\hline $\begin{array}{l}\text { *Multivariate linear regression controll } \\
\text { †First } 1 \mathrm{~cm} \text { of hair corresponds appro } \\
\text { previous } 2-3 \text { months. } \\
\text { †p value for linear trend }<0.05 \text {. } \\
\text { Subject numbers for each tertile/nicoti } \\
\text { cotinine, } 1 \text { month } n=54,42 \text {, and } 42 ; \\
\text { Higher severity of asthma scores indica } \\
\text { health status scores indicate better hec }\end{array}$ & $\begin{array}{l}y \text { to exposure during the } \\
\text { ge, } n=63 \text { per tertile; hair } \\
\text { tinine, } 2-3 \text { months, } n=42 \\
\text { ter asthma severity; higher } \\
\text { us. }\end{array}$ & $\begin{array}{l}\text { tatus, and smoking. } \\
\text { month; } 2-3 \mathrm{~cm} \text { of hair corresponds } \\
\text { month } \mathrm{n}=55,38 \text {, and } 45 \text {; hair nicot } \\
41 \text {. } \\
\text { pecific quality of life scores indicate pc }\end{array}$ & $\begin{array}{l}\text { roximately to exposure during the } \\
2-3 \text { months } n=40,42 \text {, and } 42 \text {; hair } \\
\text { quality of life; higher SF-1 } 2 \text { physical }\end{array}$ \\
\hline
\end{tabular}


Table 6 Directly measured SHS exposure and the prospective risk of admission to hospital for asthma

\begin{tabular}{|c|c|c|}
\hline Exposure/dose measurement & $\begin{array}{l}\text { Risk of hospital } \\
\text { admission } \\
\mathrm{HR}^{*}(95 \% \mathrm{Cl})\end{array}$ & $\begin{array}{l}\text { Baseline risk of hospital } \\
\text { admission (time- } \\
\text { dependent model) } \dagger \\
\text { HR }(95 \% \mathrm{CI})\end{array}$ \\
\hline \multicolumn{3}{|l|}{ Nicotine badge (previous week) } \\
\hline First tertile $\left(0-0.03 \mu \mathrm{g} / \mathrm{m}^{3}\right)$ & 1.0 (referent) & NA \\
\hline Second tertile $\left(0.04-0.13 \mu \mathrm{g} / \mathrm{m}^{3}\right)$ & $0.70(0.39$ to 1.26$)$ & NA \\
\hline Third tertile $\left(0.14-9.82 \mu \mathrm{g} / \mathrm{m}^{3}\right)$ & $0.94(0.53$ to 1.65$)$ & NA \\
\hline \multicolumn{3}{|l|}{ Hair nicotine (previous montht) } \\
\hline First tertile $(0 \mathrm{ng} / \mathrm{mg})$ & NA & 1.0 (referent) \\
\hline Second tertile $(0.01-0.12 \mathrm{ng} / \mathrm{mg})$ & NA & $3.73(1.04$ to 13.3$)$ \\
\hline Third tertile $(0.13-3.15 \mathrm{ng} / \mathrm{mg})$ & NA & $3.61(1.01$ to 12.9$)$ \\
\hline \multicolumn{3}{|l|}{ Hair nicotine (previous 2-3 monthst) } \\
\hline First tertile $(0-0.02 \mathrm{ng} / \mathrm{mg})$ & 1.0 (referent) & NA \\
\hline Second tertile $(0.03-0.19 \mathrm{ng} / \mathrm{mg})$ & $0.61(0.28$ to 1.31$)$ & NA \\
\hline Third tertile $(0.20-4.0 \mathrm{ng} / \mathrm{mg})$ & 0.88 (0.43 to 1.79$)$ & NA \\
\hline \multicolumn{3}{|l|}{ Hair cotinine (previous montht) } \\
\hline First tertile $(0-0.02 \mathrm{ng} / \mathrm{mg})$ & 1.0 (referent) & NA \\
\hline Second tertile $(0.03-0.10 \mathrm{ng} / \mathrm{ml})$ & 1.15 (0.57 to 2.33$)$ & NA \\
\hline Third tertile $(0.11-0.78 \mathrm{ng} / \mathrm{ml})$ & $1.40(0.68$ to 2.87$)$ & NA \\
\hline \multicolumn{3}{|l|}{ Hair cotinine (previous 2-3 months + ) } \\
\hline First tertile (0-0.03 ng/ml) & 1.0 (referent) & NA \\
\hline Second tertile $(0.04-0.10 \mathrm{ng} / \mathrm{ml})$ & $2.08(0.96$ to 4.54$)$ & NA \\
\hline Third tertile $(0.11-1.11 \mathrm{ng} / \mathrm{ml})$ & $1.80(0.81$ to 4.00$)$ & NA \\
\hline \multicolumn{3}{|c|}{$\begin{array}{l}\text { *Multivariate Cox proportional hazards regression analysis controlling for age, sex, race, educational attainment } \\
\text { marital status, and previous smoking history. The overall rate of readmission to hospital was } 40 \% \text { for the nicotine } \\
\text { badge group and } 38 \% \text { for the hair groups. } \\
\text { †Proportional hazards assumption was violated for this model (interaction between hair nicotine during the } \\
\text { previous month and time, } p=0.08 \text { ). The hazards ratio (HR) represents the risk of hospital admission at the baseline } \\
\text { of the prospective follow up period; the risk diminished thereafter (see text). The proportional hazards assumption } \\
\text { was not violated for the other models so time-dependent analyses are not presented. } \\
N A=\text { model not applicable (as described above). }\end{array}$} \\
\hline
\end{tabular}

additional evidence linking SHS exposure with poorer adult asthma outcomes.

The study participants lived in California where public smoking is mostly prohibited, so they had lower SHS exposure than is expected in most other geographical locations. For instance, adults who lived in Massachusetts during the 1980s had substantially higher personal badge nicotine concentrations during a typical week (median $1.7 \mu \mathrm{g} / \mathrm{m}^{3}$ and $2.8 \mu \mathrm{g} / \mathrm{m}^{3}$ in two different periods) than in our study (median $0.12 \mu \mathrm{g} / \mathrm{m}^{3}$ ). ${ }^{39}$ Other studies of persons who reside outside California also found higher hair nicotine and cotinine levels, including non-smoking pregnant women (3-7-fold higher than we observed), children with asthma (8fold higher), and persons with occupational SHS exposure (2-6-fold higher). ${ }^{1622}{ }^{40}$ Our observed negative effects of SHS exposure on adults with asthma are therefore a conservative estimate, with greater potential effects among asthmatics who live in places that allow more SHS exposure.

The impact of SHS exposure on asthma outcomes varied according to the direct exposure methods used. Some of these

\section{Main messages}

- Exposure to second hand tobacco smoke (SHS) is common among adults with asthma, with an exposure prevalence that is comparable to the general population.

- SHS exposure appears to be associated with greater asthma severity and a higher prospective risk of hospital admission for asthma. differences reflect the duration of exposure measured by each technique. Both the nicotine badge test (which measured exposure during the previous week) and the hair samples (which reflected more remote exposure) were associated with greater current asthma severity. In contrast, some hair measurements, which reflect cumulative SHS exposure during the past several months, were related to an increased risk of future hospital admission whereas the shorter term nicotine badge measurements were not. Based on these results, it seems likely that longer term cumulative SHS exposure is more likely to have an adverse effect on future asthma health outcomes such as admission to hospital, whereas asthma severity is affected by both short and longer term exposure. There did not appear to be a consistent differential impact of hair nicotine concentrations (which primarily reflect direct absorption from ambient air) and hair cotinine concentrations (which reflect hepatic metabolism of nicotine) on asthma outcomes.

The current study has limitations which may affect interpretation of the data. Although direct measurement of SHS exposure is a more accurate method than self-reporting, it is more labour intensive and requires a greater degree of commitment from study subjects. Consequently, not all eligible subjects participated in direct monitoring which could have introduced selection bias. However, the similarity of participants and non-participants reduced the likelihood of this. In addition, incorporating sample weights that account for non-response into the analysis had a negligible impact on study results (data not shown). The other consequence of lower study participation is diminished statistical power which resulted in decreased precision of effect estimates. In some cases there appeared to be a deleterious effect of SHS exposure, but the $95 \%$ confidence intervals were wide and included no association. A larger sample size might have 


\section{Policy implications}

- Asthma is a salient condition among the general public, so our findings will help support the growing movement to prohibit smoking in public places throughout the US and the rest of the world.

resulted in clearer evidence of SHS effects in these cases. Alternatively, studying the question in a geographical area where smoking is more common and SHS levels are higher might have increased statistical power. Finally, while direct SHS exposure eliminated the bias inherent in self-reported exposure, a bias termed the "healthy passive smoker effect" can still occur, meaning that more severely affected asthmatics may selectively avoid SHS exposure, attenuating the observed association between exposure and asthma health outcomes.

In addition, misclassification of asthma could affect the study results. We used inclusion criteria that mandated a hospital discharge diagnosis of asthma, but errors in discharge coding can occur. Supporting the validity of our study approach, previous investigations have used ICD-9 discharge diagnoses to define persons admitted to hospital for asthma. ${ }^{91-43}$ In addition, this approach has been validated against medical record review by our colleagues at Kaiser Permanente Northwest. ${ }^{44}$ Moreover, all subjects in the present study reported a physician diagnosis of asthma. Because our sampling strategy targeted adults with more severe asthma, these results may not be fully generalisable to persons with milder disease. In addition, KP members, because they have access to health care, may also be different from the general population of adults with asthma. Mitigating these limitations, the sociodemographic characteristics of Northern California KP members are similar to those of the regional population, with some under-representation of income extremes. ${ }^{89}$

Our results have implications for research, public health, and clinical practice. Direct SHS exposure measurement has better accuracy than self-reported exposure, but the trade off is greater cost, more commitment required from study subjects, and decreased participation rates. For a given study, investigators need to weigh the issue of accurate exposure classification against the possibility of selection bias. In terms of public health, asthma is a salient condition among the general public, so our finding that SHS negatively affects adults with asthma will help support the growing movement to prohibit smoking in public places throughout the US and the rest of the world. These results give credence to the clinical recommendation, ${ }^{45}$ initially made without the support of epidemiological evidence, that healthcare providers should screen their asthma patients for SHS exposure and counsel its avoidance.

\section{Authors' affiliations}

M D Eisner, G Lactao, Division of Occupational and Environmental Medicine and Division of Pulmonary and Critical Care Medicine, Department of Medicine, University of California, San Francisco, CA, USA

M D Eisner, G Koren, C Iribarren, Division of Research, Kaiser Permanente, Oakland, CA, USA

J Klein, Fetal Toxicology Laboratory, Motherisk, Hospital for Sick Children, Toronto, Canada

S K Hammond, School of Public Health, University of California, Berkeley, CA, USA

Dr Eisner was supported by 10RT-0108 from the Tobacco-Related Disease Research Program and K23 HL04201, National Heart, Lung, and Blood Institute, National Institutes of Health, with co-funding by the Social Security Administration.

Competing interests: none declared

\section{REFERENCES}

1 California Environmental Protection Agency. Health effects of exposure to environmental tobacco smoke. Sacramento, CA: Office of Environmental Health Hazard Assessment, 1997.

2 Blanc PD, Ellbjar S, Janson C, et al. Asthma-related work disability in Sweden. The impact of workplace exposures. Am J Respir Crit Care Med 1999; 160:2028-33.

3 Jindal SK, Gupta D, Singh A. Indices of morbidity and control of asthma in adult patients exposed to environmental tobacco smoke. Chest 1994; 106:746-9.

4 Sippel JM, Pedula KL, Vollmer WM, et al. Associations of smoking with hospital-based care and quality of life in patients with obstructive airway disease. Chest 1999;115:691-6.

5 Ostro BD, Lipsett MJ, Mann JK, et al. Indoor air pollution and asthma. Results from a panel study. Am J Respir Crit Care Med 1994;149:1400-6.

6 Eisner MD, Yelin EH, Katz PP, et al. Exposure to indoor combustion and adult asthma outcomes: environmental tobacco smoke, gas stoves, and woodsmoke. Thorax 2002;57:973-8.

7 Eisner MD, Blanc PD. Environmental tobacco smoke exposure during travel among adults with asthma. Chest 2002;122:826-8.

8 Karter AJ, Ferrara A, Liu JY, et al. Ethnic disparities in diabetic complications in an insured population. JAMA 2002;287:2519-27.

9 Krieger N. Overcoming the absence of socioeconomic data in medical records: validation and application of a census-based methodology. Am J Public Health 1992:82:703-10.

10 Eisner MD, Katz PK, Capra A, et al. Intensive care unit admission for asthma: a marker of severe disease. Am J Respir Crit Care Med 2002; 165:A121.

11 Hammond SK, Sorensen G, Youngstrom R, et al. Occupational exposure to environmental tobacco smoke. JAMA 1995;274:956-60.

12 Hammond SK, Leaderer B. A diffusion monitor to measure exposure to passive smoking. Environ Sci Technol 1987;21:494-7.

13 Eliopoulos C, Klein J, Phan MK, et al. Hair concentrations of nicotine and cotinine in women and their newborn infants. JAMA 1994;271:621-3.

14 Klein J, Forman R, Eliopoulos C, et al. A method for simultaneous measurement of cocaine and nicotine in neonatal hair. Ther Drug Monit 1994; 16:67-70.

15 Klein J, Chitayat D, Koren G. Hair analysis as a marker for fetal exposure to maternal smoking. N Engl J Med 1993;328:66-7.

16 Knight JM, Eliopoulos C, Klein J, et al. Pharmacokinetic predisposition to nicotine from environmental tobacco smoke: a risk factor for pediatric asthma. J Asthma 1998;35:113-7.

17 Nafstad P, Fugelseth D, Qvigstad E, et al. Nicotine concentration in the hair of nonsmoking mothers and size of offspring. Am J Public Health 1998;88:120-4.

18 Klein J, Koren G. Hair analysis: a biological marker for passive smoking in pregnancy and childhood. Human Exp Toxicol 1999;18:279-82.

19 Jaakkola MS, Jaakkola JJ. Assessment of exposure to environmental tobacco smoke. Eur Respir J 1997;10:2384-97.

20 Zahlsen K, Nilsen T, Nilsen OG. Interindividual differences in hair uptake of air nicotine and significance of cigarette counting for estimation of environmental tobacco smoke exposure. Pharmacol Toxicol 1996;79: 183-90.

21 Nilsen T, Zahlsen K, Nilsen OG. Uptake of nicotine in hair during controlled environmental air exposure to nicotine vapour: evidence for a major contribution of environmental nicotine to the overall nicotine found in hair from smokers and non-smokers. Pharmacol Toxicol 1994;75:136-42.

22 Eliopoulos C, Klein J, Chitayat D, et al. Nicotine and cotinine in maternal and neonatal hair as markers of gestational smoking. Clin Invest Med Medecine Clinique Experimentale 1996;19:231-42.

23 Chan D, Caprara D, Blanchette P, et al. Recent developments in meconium and hair testing methods for the confirmation of gestational exposures to alcohol and tobacco smoke. Clin Biochem 2004;37:429-38.

24 Eisner MD, Katz PP, Yelin EH, et al. Measurement of environmental tobacco smoke exposure among adults with asthma. Environ Health Perspect 2001;109:809-14.

25 Anon. Cigarette smoking among adults, United States, 1997. MMWR 1999;48:993-6.

26 Eisner MD, Yelin EH, Trupin L, et al. The influence of chronic respiratory conditions on health status and work disability. Am J Public Health 2002; $92: 1506-13$.

27 Blanc PD, Cisternas M, Smith S, et al. Asthma, employment status, and disability among adults treated by pulmonary and allergy specialists. Chest. 1996;109: 688-96; erratum, 2000;1 18:564.

28 Eisner MD, Katz PP, Yelin EH, et al. Assessment of asthma severity in adults with asthma treated by family practitioners, allergists, and pulmonologists. Med Care 1998;36:1567-77.

29 Marks GB, Dunn SM, Woolcock AJ. A scale for the measurement of quality of life in adults with asthma. J Clin Epidemiol 1992;45:461-72.

30 Katz PP, Eisner MD, Henke J, et al. The Marks Asthma Quality of Life Questionnaire: further validation and examination of responsiveness to change. J Clin Epidemiol 1999:52:667-75.

31 Marks GB, Dunn SM, Woolcock AJ. An evaluation of an asthma quality of life questionnaire as a measure of change in adults with asthma. J Clin Epidemiol 1993;46: $1103-11$. 
32 Ware J Jr, Kosinski M, Keller SD. A 12-Item Short-Form Health Survey: construction of scales and preliminary tests of reliability and validity. Med Care 1996;34:220-33.

33 Osman LM, Calder C, Robertson R, et al. Symptoms, quality of life, and health service contact among young adults with mild asthma. Am J Respir Crit Care Med 2000;161:498-503.

34 Iribarren C, Friedman GD, Klatsky AL, et al. Exposure to environmental tobacco smoke: association with personal characteristics and self reported health conditions. J Epidemiol Community Health 2001;55:721-8.

35 Schoenfeld D. Partial residuals for the proportional hazards regression model. Biometrika 1982;69:239-41.

36 Allison PD. Survival analysis using the SAS system. Cary, NC: SAS Institute Inc, 1995.

37 Weiss ST, Utell MJ, Samet JM. Environmental tobacco smoke exposure and asthma in adults. Environ Health Perspect 1999;107(Suppl 6):891-5.

38 Coultas DB. Health effects of passive smoking: 8. Passive smoking and risk of adult asthma and COPD: an update. Thorax 1998;53:381-7.
39 Coghlin J, Hammond SK, Gann PH. Development of epidemiologic tools for measuring environmental tobacco smoke exposure. Am J Epidemiol 1989;130:696-704.

40 Dimich-Ward H, Gee H, Braver M, et al. Analysis of nicotine and cotinine in the hair of hospitality workers exposed to environmental tobacco smoke. $J$ Occup Environ Med 1997;39:946-8.

41 Lieu TA, Capra AM, Quesenberry CP, et al. Computer-based models to identify high-risk adults with asthma: is the glass half empty of half full? J Asthma 1999;36:359-70.

42 Eisner MD, Lieu TA, Chi F, et al. Beta agonists, inhaled steroids, and the risk of intensive care unit admission for asthma. Eur Respir J 2001;17:233-40.

43 Spitzer WO, Suissa S, Ernst $P$, et al. The use of beta-agonists and the risk of death and near death from asthma. N Engl J Med 1992;326:501-6.

44 Osborne ML, Vollmer WM, Buist AS. Diagnostic accuracy of asthma within a health maintenance organization. J Clin Epidemiol 1992;45:403-11.

45 National Heart, Lung, and Blood Institute. Guidelines for the diagnosis and management of asthma. National Asthma Education Program. Expert Panel Report. J Allergy Clin Immunol 1991;88:425-534.

\section{LUNG ALERT}

The renin-angiotensin system: a potential therapeutic target in ARDS?

$\Delta$ Imai Y, Kuba K, Rao S, et al. Angiotensin-converting enzyme 2 protects from severe acute lung failure. Nature 2005;436:112-6

This paper reports a critical role of the renin-angiotensin system (RAS) in the pathogenesis of acute lung injury (ALI) in the mouse. Angiotensin converting enzyme (ACE) and its counter-regulatory homologue ACE2 determine the levels of angiotensin II (ATII) within the lung. By a series of logical stepwise experiments, manipulating key components of the RAS, the authors demonstrate a pivotal role of ATII (upregulated by ACE, downregulated by ACE2) in the pathogenesis of experimentally induced ALI.

Using accepted models of ALI (acid aspiration, endotoxin, and caecal ligation and perforation induced sepsis), they examined sequentially the effects of ACE2, ACE, and ATII manipulation on the severity of the induced lung injury. ACE2 knockout mice (with upregulated ATII levels) had significantly worse ALI than wild type mice (as defined by the end points of oxygenation, compliance, vascular permeability and inflammation). Treatment with recombinant ACE2 partially protected against lung injury in both wild type and ACE2 knockout mice. Importantly, ACE2 was also downregulated in wild type mice with ALI. In contrast, ACE knockout mice (with downregulated ATII levels) were markedly protected against ALI compared with wild type mice. Finally, they showed that the deleterious effects of ATII were mediated via the ATII type la receptor (ATlaR) in the mouse lung. Pharmacological inhibition of ATlaR resulted in significantly improved lung function in both ACE2 knockout and wild type mice.

If these findings are confirmed in human ALI/ARDS, the RAS may offer a new therapeutic target for this devastating condition.

J Elder 